This item was submitted to Loughborough's Research Repository by the author.

Items in Figshare are protected by copyright, with all rights reserved, unless otherwise indicated.

\title{
A dental stool with chest support reduces lower back muscle activation
}

PLEASE CITE THE PUBLISHED VERSION

http://dx.doi.org/10.1080/10803548.2016.1153223

\section{PUBLISHER}

Taylor \& Francis (@ Central Institute for Labour Protection)

\section{VERSION}

AM (Accepted Manuscript)

\section{PUBLISHER STATEMENT}

This work is made available according to the conditions of the Creative Commons Attribution-NonCommercialNoDerivatives 4.0 International (CC BY-NC-ND 4.0) licence. Full details of this licence are available at: https://creativecommons.org/licenses/by-nc-nd/4.0/

\section{LICENCE}

CC BY-NC-ND 4.0

\section{REPOSITORY RECORD}

Tran, Viet, Reid Turner, Andrew MacFadden, Stephen M. Cornish, Dale Esliger, Kuni Komiyama, and Philip D. Chilibeck. 2019. "A Dental Stool with Chest Support Reduces Lower Back Muscle Activation”. figshare. https://hdl.handle.net/2134/21081. 
1

2

4

5

6

\title{
A dental stool with chest support reduces lower back muscle activation
}

Viet Tran ${ }^{\mathrm{a}}$, Reid Turner ${ }^{\mathrm{a}}$, Andrew MacFadden ${ }^{\mathrm{b}}$, Stephen M. Cornish ${ }^{\mathrm{c}^{*}}$, Dale Esliger ${ }^{\mathrm{d}}$, Kunio Komiyama $^{\mathrm{a}}$, and Philip D. Chilibeck ${ }^{\mathrm{e}}$

5

${ }^{\mathrm{a} C o l l e g e ~ o f ~ D e n t i s t r y, ~ U n i v e r s i t y ~ o f ~ S a s k a t c h e w a n, ~ S a s k a t o o n, ~ C a n a d a, ~ S 7 N ~ 5 E 4 ~}$

${ }^{\mathrm{b}}$ College of Arts and Sciences, University of Saskatchewan, Department of Psychology, Saskatoon, Canada, S7N 5A5

${ }^{\mathrm{C}}$ Faculty of Kinesiology and Recreation Management, University of Manitoba, Winnipeg, 10 Canada, R3T 2N2

\author{
${ }^{\mathrm{d}}$ School of Sport, Exercise and Health Sciences, Loughborough University, Leicestershire, \\ United Kingdom, LE11 3TU \\ ${ }^{\mathrm{e}}$ College of Kinesiology, University of Saskatchewan, Saskatoon, Canada, S7N 5B2
} 4

Running Head: Dental stool and muscle activation 6

*Corresponding Author:

Stephen M. Cornish, $\mathrm{PhD}$

117 Frank Kennedy Centre

Faculty of Kinesiology \& Recreation Management

1 University of Manitoba

Winnipeg, Manitoba, CANADA R0A 0A2

Email: Stephen.Cornish@umanitoba.ca 


\section{Abstract}

Activation of back musculature during work tasks leads to fatigue and potential

26 injury. This is especially prevalent in dentists who perform much of their work from a

27 seated position. We examined the use of an ergonomic dental stool with mid-sternum chest

28 support for reducing lower back muscle activation. Electromyography (EMG) of lower

29 back extensors was assessed from 30 dental students for 20 seconds during three conditions

30 in random order: 1) sitting up-right at $90^{\circ}$ of hip flexion in a standard stool, 2) leaning

31 forward at $80^{\circ}$ of hip flexion on the standard stool, and 3) leaning forward at $80^{\circ}$ of hip

32 flexion while sitting on the ergonomic stool. Muscular activity of the back extensors was

33 reduced when using the ergonomic stool compared to the standard stool, by $33-50 \%$

$34(\mathrm{p}<0.01)$. This suggests a potential musculoskeletal benefit with use of a dental stool with 35 mid-sternum chest support.

36

37 Keywords: spine, posture, fatigue, injury 


\section{2. Material and Methods}

58

\subsection{Participants}

\section{Introduction}

The profession of general dentistry is at a high risk for development of musculoskeletal disorders because dentists require optimal visualization of a relatively small operative field resulting in prolonged and static maintenance of posture [1-3]. This type of strain places the dental practitioner at an increased risk of developing lower back pain. The prevalence of back pain among dentists ranges from 36 to $72 \%[1,2,4,5]$.

A variety of ergonomically designed dental stools have been proposed for alleviating musculoskeletal disorders [6,7]. Hardage et al. [6] showed that low back muscle activity could be reduced with a back support; however, this may be impractical during practice when a dentist must lean forward to work on a patient. Parsell et al. [7] showed that neither rigid arm support nor chest support with mobile arm support on a dental stool was effective for reducing lower back muscle activity. They suggested that the dentists’ unfamiliarity with the mobile arm support may have increased low back activation, cancelling any benefit from chest support. The objective of the present investigation was to compare the degree of back musculature activation in dental students while leaning forward on a regular dental stool and on an ergonomically-altered dental stool with mid-sternum chest support. We hypothesized that the ergonomic stool would result in significantly less lower-back muscle activation.

A total of 30 (16 male and 14 female) participants were tested in this study. The participants ranged from second to fifth year dental students from the College of Dentistry 
61 at the University of Saskatchewan. Participants were 21 to 30 years of age with an average

62 of 24 (SD 3) years. All participants were considered healthy with no previous history of

63 back injury or complaint and absence of any known systemic musculoskeletal disorders.

64 All participants signed an informed consent form and the study was approved by our 65 university's human ethics review board.

66

67 2.2. Muscles investigated

68 Dorsal muscle activity was recorded using electromyography (EMG) from two back

69 muscles, the longissimus thoracis and iliocostalis lumborum. The iliocostalis lumborum is

70 a global stabilizer while the longissimus thoracis is considered a global mobilizer [8].

71 These two muscles, along with the spinalis thoracis, form the erector spinae muscle group,

72 which is involved in vertebral extension, and lay within a fascial compartment between the

73 posterior and anterior layers of the thoracolumbar fascia and traverses the length of the

74 back. These two posterior extensor muscles were chosen due to their superficial nature

75 allowing for relative ease of landmark placement for EMG surface electrodes.

76

77

\subsection{Experimental method}

78 A two lead analog surface EMG (Bagnoli-2, Delsys Inc., Boston, Mass.) along with the

79 EMGworks computer software program was used to measure muscle activation. Two

80 electrodes, $10 \mathrm{~mm}$ apart, were attached at each the level of L2 and L3 of the right

81 iliocostalis lumborum and longissimus thoracis muscles respectively. A reference electrode

82 (ground) was attached to the kneecap. The EMG main amplifier unit included single

83 differential electrodes with a bandwidth of 20 (5) Hz to 450 (50) Hz, a 12 dB/ octave cut- 
84 off slope, and a maximum output voltage frequency range $\pm 5 \mathrm{~V}$. The overall amplification

85 or gain per channel was 10,000 . The system noise was $<1.2 \mu \mathrm{V}$ (rms) for the specified

86 bandwidth. The electrodes were two silver bars (10 mm $11 \mathrm{~mm}$ diameter $)$ spaced $10 \mathrm{~mm}$

87 apart, with a common mode rejection ratio of $92 \mathrm{~dB}$. The EMG was recorded as raw EMG

88 (V) and stored in the computer for analysis. The sampling rate was set at 1,024 Hz which is

89 more than double the highest frequency cut-off value of the bandwidth $(450 \mathrm{~Hz})$ as required

90 by the Nyquist criterion. The raw EMG data were then used to calculate root mean square

91 (RMS) using the EMGworks software.

92 Participants' muscle activity was tested using two dental stool designs. The first

93 standard dental stool was a model “G” serial \#1119 (Ritter, Canada). The second stool had

94 a similar seat but was modified to include a chest support, located at mid-sternum, aimed at

95 minimizing lower back strain. The function of this anterior chest support is to allow the

96 operator to transfer their weight onto the chest pad in turn reducing the strain placed on the

97 lower back.

Muscle activity was assessed during three conditions (Figure 1), in a randomized, counter-balanced order. In the first condition participants were measured sitting at $90^{\circ}$ of 100 hip flexion and knee flexion on a standard stool (Condition 1; Figure 1a) with their hands 101 out in front of them as though they were working on a patient (i.e. elbows flexed at $90^{\circ}$, 102 with forearms unsupported, hands in a neutral position). A consistent $90^{\circ}$ posture was 103 verified using a goniometer. This $90^{\circ}$ posture was used as a baseline to simulate what 104 would be considered perfect posture; a posture that places minimal strain on the lower 105 back. In the second condition participants leaned forward to $80^{\circ}$ of hip flexion on the 106 standard dental stool and placed their hands out in front of them, again with elbows flexed 
107 at $90^{\circ}$ with forearms unsupported, and hands in a neutral position (Figure 1b). The final 108 test condition had the participants seated on the modified dental stool (Condition 3) with $10980^{\circ}$ of hip flexion, the same as the second condition, but this time supported in the position 110 by a chest pad (Figure 1c). EMG was collected during muscle contractions for all three 111 isometric conditions and was measured for a period of 20 seconds.

\subsection{Statistics}

A repeated measures ANOVA was used to determine differences in EMG values

115 between conditions for each muscle group. The alpha level was set at 0.025 to adjust for

116 the number of statistical tests (i.e. 0.05/2) to reduce chance of type I error. When warranted,

117 post-hoc analysis was performed using Tukey’s HSD test to determine the differences

118 between the three conditions. All analyses were done using (Statistica version 7, StatSoft

119 Inc., Tulsa, Oklahoma). All data are reported as mean (SD).

\section{Results}

A main effect of condition was observed for both muscle groups $(\mathrm{p}<0.01)$. For each

123 muscle group, the Tukey’s post-hoc test indicated muscle activity was highest in condition

1242 (i.e. standard dental stool, hips at $80^{\circ}$ flexion) when compared with conditions 1 (i.e.

125 standard dental stool, hips at $90^{\circ}$ flexion) and 3 (dental stool with chest support, hips at $80^{\circ}$

126 flexion $)(\mathrm{p}<0.01$; Figure 2). Iliocostalis lumborum and longissimus thoracis muscle activity

127 was reduced by approximately 33\% and 50\% respectively when comparing condition 2 to

128 condition 3. 
130

131

132

133

134

135

136

137

138

139

140

141

142 determined that EMG activity of the lower back was reduced by about $49 \%$ with the lower

143 back support. Participants were evaluated in an upright position (i.e. with hips at a $90^{\circ}$

144 angle) and hands resting on the knees. One could argue that this might not be the best

145 simulation of a dentist's position while working on a patient. A proper simulation would

146 require a forward lean with arms extended. Parsell et al. [7] found that stools with rigid arm

147 supports and with chest support combined with mobile arm support had no effect on

148 activation of lower back musculature. They suggested that the lack of familiarity with the

149 mobile arm support may have increased lower back muscle activation in their participants,

150 cancelling out any benefit of the chest support. They only studied 13 participants and

151 therefore, their study may have been underpowered to detect statistical differences between 
152 their chairs. Our study indicates that chest support on a dental stool is effective for reducing 153 muscle activity of the lower back.

A limitation of our study was that muscle EMG activity was only recorded for a 20

155 second interval. The short time interval was utilized in order to obtain pilot data that would 156 be able to determine the practical nature of adding a chest support to a standard dental

157 stool. The reality of dental work suggests dental practitioners will sustain strained static 158 positions for a much longer time than measured.

159 Our results imply that chest support on a dental stool may result in reduced lower 160 back strain which could lead to reduced lower back pain if used in a clinical setting. This 161 inference is suggested but it is acknowledged that our study did not test this hypothesis 162 directly. Further, certain positions of the dentist during dental procedures may require 163 more hip flexion or more exaggerated trunk flexion or rotation to gain direct vision or 164 proper instrument orientation. Thus, the chest support may interfere with some of these 165 movements which may limit its application in a clinical setting. A more extensive clinical trial would be needed to verify that a measureable 167 reduction in back muscle strain can be demonstrated in practitioners using the chest support 168 while performing dental procedures; however, there does remain potential for a health 169 benefit with the use of an ergonomically designed operator stool for dental professionals. 170 When abnormal postures are not necessary, the chest support stool could permit dental 171 practitioners to operate in a more comfortable and relaxed manner which may lead to a 172 reduction in lower back pain in this population.

\section{5. Conclusion}


Our results suggest that the use of a chest support during hip flexion reduces the 176 activity of two major erector spinae muscles. This may be one method of modifying the 177 environment of dental professionals to reduce the risk of lower back injury in this highly 178 susceptible group. Further clinical trials evaluating both environmental (modification of 179 dental stools) and personal (improved fitness levels and core musculature strength) factors 180 will help determine which interventions are effective for reducing the risk of lower back 181 pain in dental practitioners. 


\section{References}

1. Lalumandier, J.A., McPhee, S.D., Parrott, C.B., \& Vendemia, M. Musculoskeletal pain: prevalence, prevention, and differences among dental office personnel. General Dentistry. 2001; 49: 160-166.

2. Marshall, E.D., Duncombe, L.M., Robinson, R.Q., \& Kilbreath, S.L. Musculoskeletal symptoms in New South Wales dentists. Australian Dental Journal. 1997; 42: 240-246.

3. Milerad, E., Ericson, M.O., Nisell, R., \& Kilbom, A. (1991). An electromyographic study of dental work. Ergonomics. 1991; 34: 953-962.

4. Dajpratham, P., Ploypetch, T., Kiattavorncharoen, S., \& Boonsiriseth, K. Prevalence and associated factors of musculoskeletal pain among the dental personnel in a dental school. Journal of the Medical Association of Thailand. 2010; 93: 714-721.

5. Hayes, M., Cockrell, D., \& Smith, D.R. A systematic review of musculoskeletal disorders among dental professionals. International Journal of Dental Hygiene. 2009; 7: 159-165.

6. Hardage, J.L., Gildersleeve, J.R., \& Rugh, J.D. Clinical work posture for the dentist: an electromyographic study. Journal of the American Dental Association. 1983; 107: 937-939.

7. Parsell, D.E., Weber, M.D., Anderson, B.C., \& Cobb, G.W., Jr. (2000). Evaluation of ergonomic dental stools through clinical simulation. General Dentistry. 2000; 48: $440-444$.

8. Bergmark, A. Stability of the lumbar spine. A study in mechanical engineering. Acta Orthopaeidica Scandinavica Supplementum. 1989; 230: 1-54. 
206

207

208

209

210

211

212
9. Al Wazzan, K.A., Almas, K., Al Shethri, S.E., \& Al-Qahtani, M.Q. Back and neck problems among dentists and dental auxiliaries. Journal of Contemporary Dental Practice. 2001; 2: 17-30. 


\section{Figure Captions}

214

215 Figure 1. The three different testing conditions: a) Condition 1: hips, knees, and elbows at

$21690^{\circ}$ flexion b) Condition 2: hips at $80^{\circ}$ flexion, and knees and elbows at $90^{\circ}$ flexion c)

217 Condition 3: Identical to position 2, except with mid-sternum chest support.

218

219 Figure 2. Average root mean square EMG activity of a) longissimus thoracis; and b)

220 iliocostalis lumborum over 20 seconds in three conditions. *Significantly greater muscle

221 activity in condition 2 (80 $80^{\circ}$ hip flexion, no support) when compared to condition 1 ( $90^{\circ}$ hip

222 flexion, no support) and condition $3\left(80^{\circ}\right.$ hip flexion, chest support) $(\mathrm{p}<0.01)$. Data are

223 presented as mean \pm SD.

224

225 
Figure 1 a.

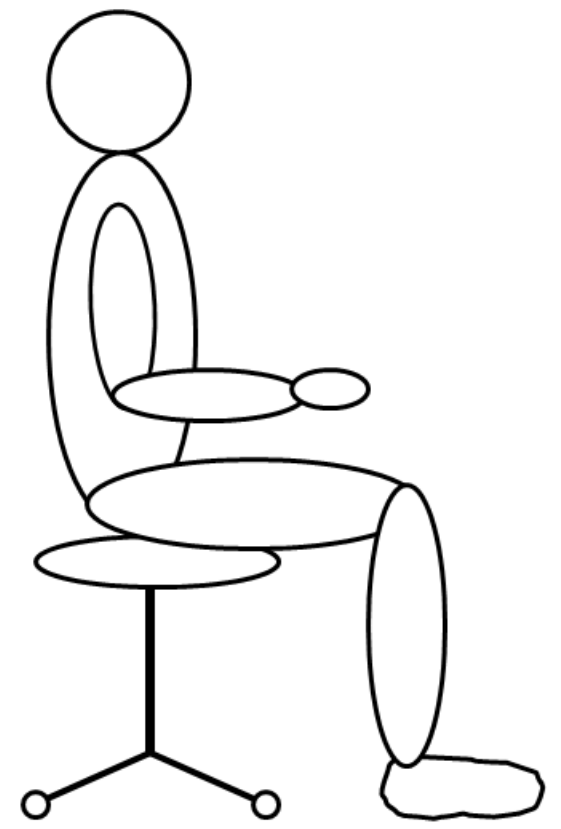


14

Figure $1 \mathrm{~b}$.

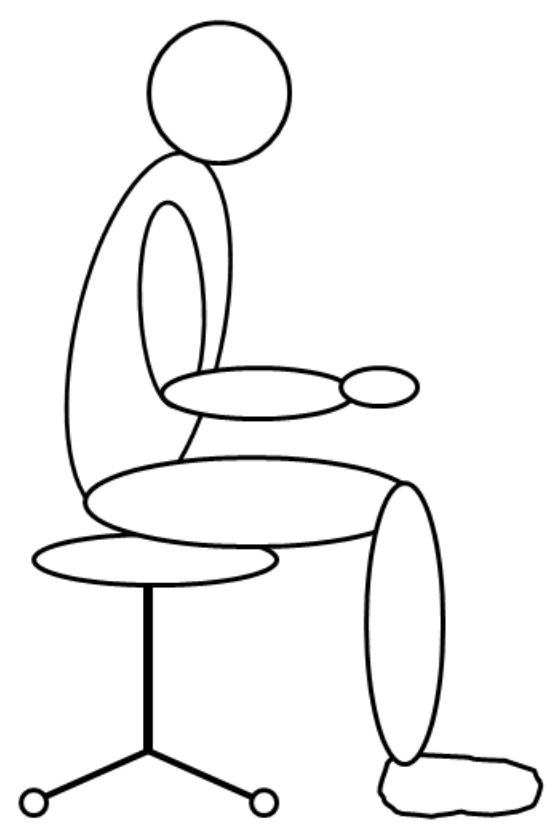

227 
15

Figure $1 \mathrm{c}$.

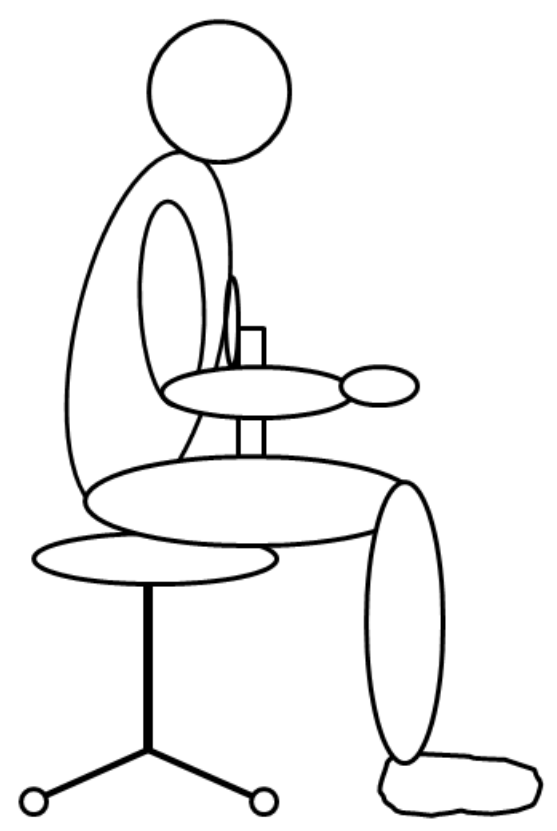

228 
229 Figure 2a

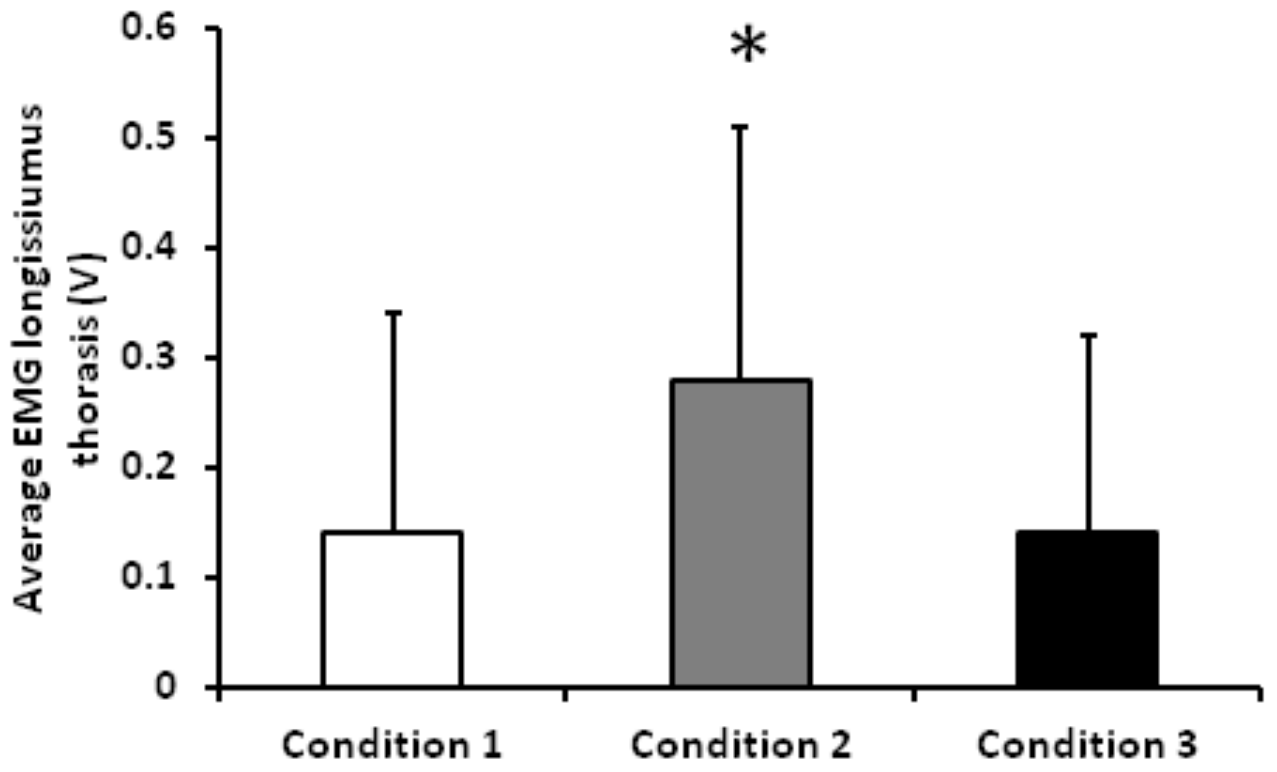


231 Figure 2b

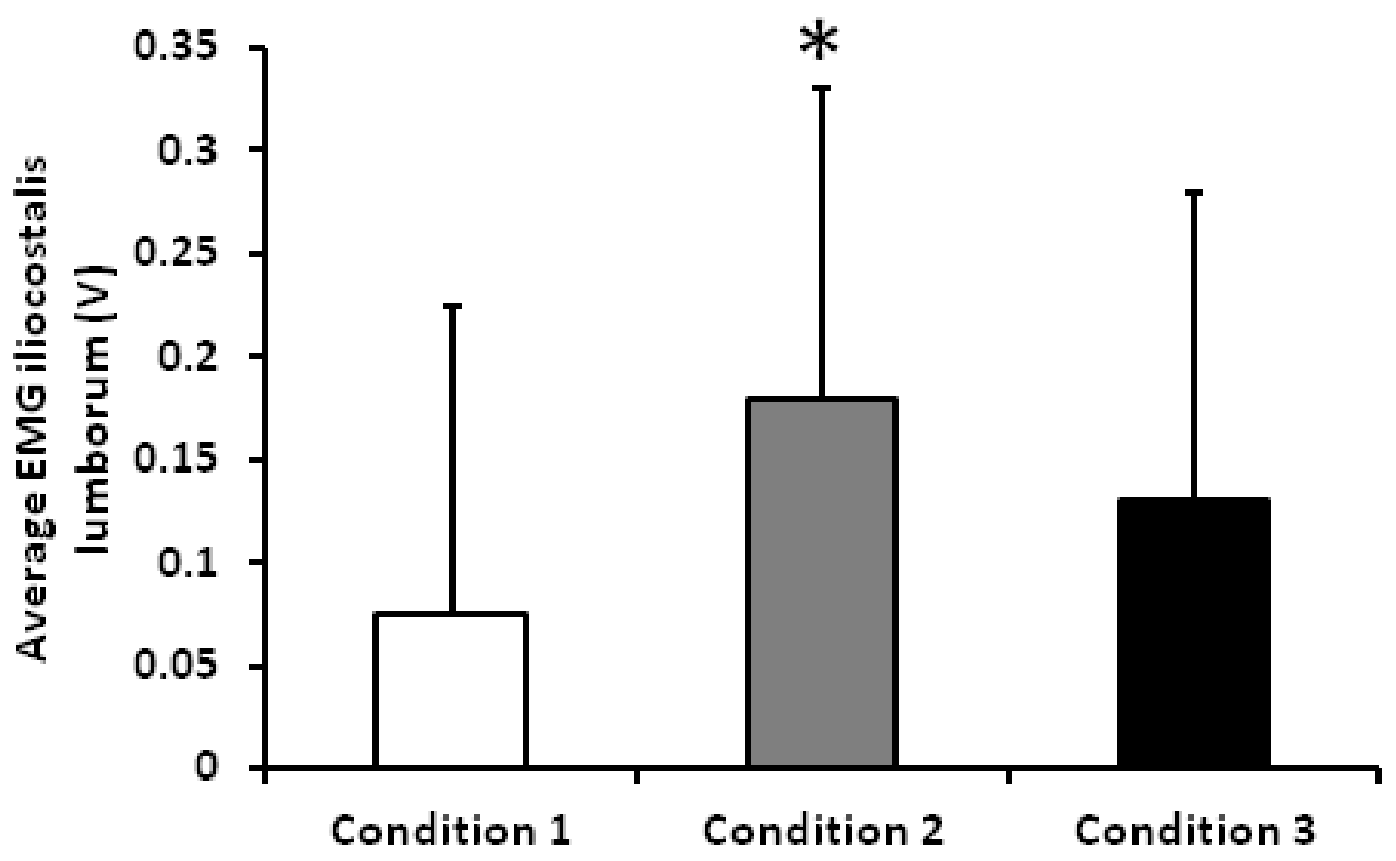

